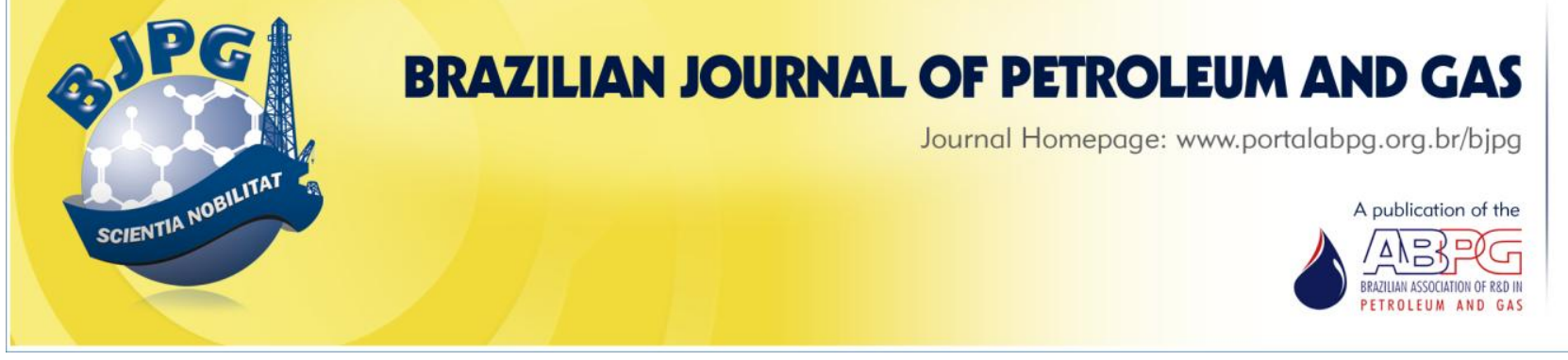

\title{
CATALYTIC CONVERSION OF CHLOROMETHANE TO METHANOL AND DIMETHYL ETHER OVER TWO CATALYTIC BEDS: A STUDY OF ACID STRENGTH
}

\author{
${ }^{\mathrm{a}}$ Fernandes, D. R.; ${ }^{\mathrm{a}}$ Leite, T. C. M., ${ }^{\mathrm{a}}$ Mota, C. J. A. ${ }^{1}$ \\ ${ }^{\text {a }}$ Universidade Federal do Rio de Janeiro, Instituto de Química
}

\begin{abstract}
The catalytic hydrolysis of chloromethane to methanol and dimethyl ether (DME) was studied over metalexchanged Beta and Mordenite zeolites, acidic MCM-22 and SAPO-5. The use of a second catalytic bed with HZSM-5 zeolite increased the selectivity to DME, due to methanol dehydration on the acid sites. The effect was more significant on catalysts presenting medium and weak acid site distribution, showing that dehydration of methanol to DME is accomplished over sites of higher acid strength.
\end{abstract}

\section{KEYWORDS}

natural gas conversion; chloromethane; zeolites; methanol; dimethyl ether

\footnotetext{
${ }^{1}$ To whom all correspondence should be addressed.

Address: Universidade Federal do Rio de Janeiro, Instituto de Química. Av Athos da Silveira Ramos 149, CT Bloco A, 21941-909, Rio de Janeiro, Brazil |e-mail: cmota@iq.ufri.br doi:10.5419/bjpg2010-0009
} 


\section{INTRODUCTION}

The production of methanol and dimethyl ether (DME) from natural gas has been the subject of great industrial interest. These oxygenates have high commercial value, because they can be used as liquid fuels and raw material for petrochemicals. Besides these two applications, these oxygenates can be used to indirectly transport natural gas, avoiding high costs and complex engineering operations of gas pipes and liquefaction, especially in remote regions.

Methane is the major component of natural gas. However, its high thermodynamic stability and reduced reactivity toward most acids, bases and oxidizing agents, makes the chemical transformation of the natural gas a difficult task. The most common pathway for transforming natural gas is reforming, which produces syngas, a mixture of carbon monoxide and hydrogen (Ross, 2005). Syngas might then be used in the FischerTropsch process (Tijm et al., 2001) to produce gasoline- and diesel-range hydrocarbons, as well as in methanol production, with the use of copperand zinc-based catalysts (Lersch and Banderman, 1991). The main problem associated with natural gas reforming is the high endothermicity of the reaction, which demands a great amount of energy, consequently increasing the operation costs. Roughly, about half of the costs of gas to liquids (GTL) processes accounts for the syngas production, which might impact the economic feasibility of natural gas transformation in valuable fuel and petrochemical feedstock.

Zeolite catalysts can be used to transform chloromethane into gasoline-range hydrocarbons (Tijm et al., 2001). However, alkyl chlorides are also found as byproducts (White et al., 1992), probably arisen from $\mathrm{HCl}$ addition to olefins. Controlling the reaction conditions and improving catalyst structure favor the reaction to formation of light olefins (Sun et al, 1993), such as ethene and propene, as main products, being an alternative pathway for these petrochemicals from natural gas.

Halogenation of methane is a well-known reaction. Chlorination is exothermic by $24 \mathrm{kcal} \mathrm{mol}^{-}$ 1 , whereas bromination releases $6 \mathrm{kcal} \mathrm{mol}^{-1}$ of energy. Both reactions can be performed in industrial scale to produce the halomethane derivatives, either through direct reaction of natural gas with the halogens, or through oxyhalogenation processes, using $\mathrm{HCl}$ or $\mathrm{HBr}$ and air. In addition, the electrophilic halogenation of methane can be performed with the use of Lewis acid catalysts, yielding monohalomethane derivatives in high selectivity (Bucsi and Olah, 1992; Olah et al., 1985). Thus, the development of processes of halomethane transformation would avoid syngas, and may reduce the economical drawbacks and high energy consumption associated with natural gas transformation.

Olah and collaborators reported the conversion of halomethanes to methanol and dimethyl ether over $\mathrm{Al}_{2} \mathrm{O}_{3}$ (Bucsi and Olah, 1992; Olah et al., 1985), as well as a non aqueous procedure using copper oxide and $\mathrm{SbF}_{5}$ supported on graphite (Olah e Bukala, 1990). Zhou and coworkers (2003) developed a process to convert methane to dimethyl ether involving bromine and metal oxides. $\mathrm{Xu}$ and collaborators (2005) studied a process to convert methane to dimethyl ether by a non syngas process, through the hydrolysis of bromomethane on ruthenium catalysts, under batch reaction conditions.

We have studied the interaction of alkylhalides with metal-exchanged zeolites (Correa and Mota, 2002; Franco et al., 2008) and applied this procedure in alkylations (Bidart et al., 2001; Rosenbach and Mota, 2005) and chloromethane transformation to ethene and propene (Noronha et al., 2005). Recently, we reported a study on the catalytic hydrolysis of chloromethane to methanol and dimethyl ether over metal-exchanged zeolite $Y$ (Fernandes et al., 2009). In the present work, we show that different metal-exchanged zeolites are able to hydrolyze chloromethane to methanol and DME (scheme 1), at mild temperatures and atmospheric pressure. The DME selectivity could be improved with the use of a second catalytic bed packed with HZSM-5. A comparison of product selectivity against the acid strength of the catalyst was established.

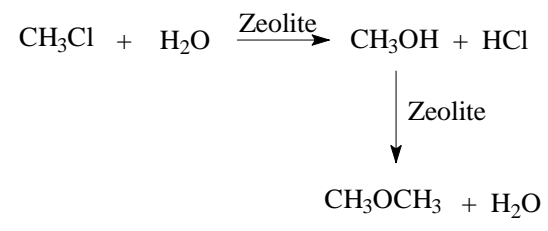

Scheme 1. Conversion of chloromethane to methanol and dimethyl ether over zeolite catalyst. 


\section{EXPERIMENTAL}

The catalytic hydrolysis of chloromethane was studied over zinc and iron-exchanged Beta (BEA) and copper and iron-exchanged Mordenite (MOR) zeolites. The detailed exchange procedure was reported elsewhere (Franco et al., 1995). In addition, the acidic form of $\mathrm{MCM}-22$ zeolite (Si/AI = 14) and SAPO-5 (Si/AI $=0.2)$ were also tested. These molecular sieves were prepared according to literature procedures (Corma et al., 1995). Table 1 shows the chemical analysis and textural properties of the catalysts used.

Table 1. Chemical and textural analysis of the catalysts.

\begin{tabular}{lccc}
\hline Catalyst & Si/Al & $\begin{array}{c}\text { Metal Content } \\
\%\end{array}$ & $\begin{array}{c}\text { BET area } \\
\mathbf{m}^{\mathbf{2}} \boldsymbol{g}^{-1}\end{array}$ \\
\hline FeBEA & 5.2 & 16 & - \\
ZnBEA & 5.2 & 15 & - \\
FeMOR & 5.2 & 11 & 365 \\
CUMOR & 5.2 & 20 & 330 \\
MCM-22 & 14 & - & - \\
SAPO-5 & 0.2 & - & 140 \\
HZSM-5 & 14 & - & 374 \\
\hline
\end{tabular}

The catalytic hydrolysis of chloromethane was carried out in a continuous flow, fixed-bed unit, coupled on line with a capillary gas chromatograph.
The catalyst was initially pre-treated under flowing nitrogen $\left(40 \mathrm{~mL} \mathrm{~min}^{-1}\right)$ at $773 \mathrm{~K}$ during 60 minutes, according to a temperature program (room temperature up to $473 \mathrm{~K}$, remaining at this temperature for 30 minutes, and then up to $773 \mathrm{~K}$, at $2 \mathrm{~K} / \mathrm{min}$ ). The reactor was then cooled to the reaction temperature, when the nitrogen flow was replaced with a flow $\left(40 \mathrm{~mL} \mathrm{~min}^{-1}\right)$ of chloromethane in helium (8 $\mathrm{mol} \%$ ). Water was simultaneously introduced in the reactor by means of a syringe pump. The water $/ \mathrm{CHCl}_{3}$ flow was adjusted to achieve a molar ratio of 3 . A second catalyst bed, packed with HZSM-5 $(\mathrm{Si} / \mathrm{Al}=14)$ zeolite, was used, with glass wood separating both catalysts. The pre-activation of the catalysts, reaction temperature and WHSV were the same as in the case of using only one bed. An U-tube packed with $\mathrm{CaO}$ was placed just after the reactor to trap the $\mathrm{HCl}$ formed and any excess water. In control experiments, it was shown that neither chloromethane, nor oxygenated products were significantly adsorbed over the $\mathrm{CaO}$ bed at room temperature. Product analyses were carried out in a capillary gas chromatograph using a flame ionization detector and a DB-624 column (cyanopropyl-phenyl-methyl-polysiloxane).

Conversion and selectivity were taken from the chromatographic analyses, after correction for the response factors. Blank reactions were carried out by replacing the catalyst bed with glass spheres.

Table 2. Hydrolysis of chloromethane over different zeolites at $543 \mathrm{~K}$.

\begin{tabular}{|c|c|c|c|c|c|c|c|c|}
\hline \multirow[b]{2}{*}{ Catalyst } & \multirow[b]{2}{*}{ Bed } & \multirow{2}{*}{$\begin{array}{c}\text { WHSV } \\
\left(h^{-1}\right)\end{array}$} & \multirow{2}{*}{$\begin{array}{c}\text { Conversion } \\
\text { (\%) }\end{array}$} & \multicolumn{5}{|c|}{ Selectivity (\%) } \\
\hline & & & & $\mathrm{CH}_{3} \mathrm{OCH}_{3}$ & $\mathrm{CH}_{3} \mathrm{OH}$ & $\mathrm{C}_{2}=$ & $\mathrm{C}_{3}{ }^{=}$ & $\mathrm{C}_{4}^{+}$ \\
\hline CuMOR & 1 & 9.13 & 10.0 & 11 & 89 & - & - & - \\
\hline CuMOR/ HZSM-5 & 2 & - & 3.7 & 28 & 72 & - & - & - \\
\hline FeMOR & 1 & 9.19 & 4.7 & 5 & 79 & 4 & 9 & 3 \\
\hline FeMOR/ HZSM-5 & 2 & - & 5.6 & 23 & 77 & - & - & - \\
\hline ZnBEA & 1 & 10.4 & 7.5 & 23 & 77 & - & - & - \\
\hline ZnBEA/ HZSM-5 & 2 & - & 5.0 & 24 & 76 & - & - & - \\
\hline FeBEA & 1 & 9.72 & 11.0 & 22 & 78 & - & - & - \\
\hline FeBEA/ HZSM-5 & 2 & - & 4.0 & 27 & 73 & - & - & - \\
\hline MCM-22 & 1 & 9.68 & 6.0 & 7 & 93 & - & - & - \\
\hline MCM-22/ HZSM-5 & 2 & - & 2.5 & 29 & 71 & - & - & - \\
\hline SAPO-5 & 1 & 8.84 & 5.0 & - & 100 & - & - & - \\
\hline SAPO-5/ HZSM-5 & 2 & - & 4.5 & 18 & 82 & - & - & - \\
\hline Blank & & - & 0.3 & - & 100 & - & - & - \\
\hline
\end{tabular}




\section{RESULTS AND DISCUSSION}

Table 2 shows the results of chloromethane hydrolysis over all catalysts used at $543 \mathrm{~K}$. Compared to the blank reaction, all catalysts were active for chloromethane hydrolysis. Neither appreciable deactivation of the catalysts nor selectivity changes were observed during the runs, which normally last 120 minutes.

Dimethyl ether is normally formed through the acid-catalyzed dehydration of methanol (Xu et al., 1997). To improve the selectivity to dimethyl ether (DME), we carried out the chloromethane hydrolysis over two catalytic beds, with HZSM-5 zeolite packed in the second bed. Figure 1 shows the results at $543 \mathrm{~K}$. One can see that in all cases the DME selectivity was improved, indicating that the methanol formed in the first catalytic bed was subsequently dehydrated to DME on the second catalytic bed, containing HZSM-5 zeolite. No detectable secondary products, such as olefins, were observed in these experiments, but increasing temperature might lead to appearance of hydrocarbons in the products. The most remarkable result was with the use of SAPO-5. This catalyst was inactive toward methanol dehydration to DME, but inclusion of a second catalytic bed with HZSM-5 led to a selectivity of more than $15 \%$ in DME. Indeed, acidity measurements, using temperature programmed desorption of $n$ butylamine (Gonçalves et al., 2008), revealed that most of the base desorbs in the temperature range between 323 and $423 \mathrm{~K}$ from SAPO-5, indicating the presence of weak acid sites. On the other hand, on HZSM-5 the majority of the n-butylamine desorbs between $623-823 \mathrm{~K}$. Table 3 shows the results of acid strength measurement based on nbutylamine thermodesorption. It can be seen that MCM-22 showed an intermediate acidity compared to SAPO-5 and HZSM-5, with most of the sites retaining the base between 423-623 K. These results explain the DME selectivity on the acidic catalyst. The acid strength of SAPO-5 is not high enough to dehydrate methanol under the reaction conditions used, whereas MCM-22 presents low selectivity to DME due to its moderate acidity. The selectivity might be increased with the use of a second catalytic bed containing HZSM-5, which possesses a higher distribution of strong acid sites.

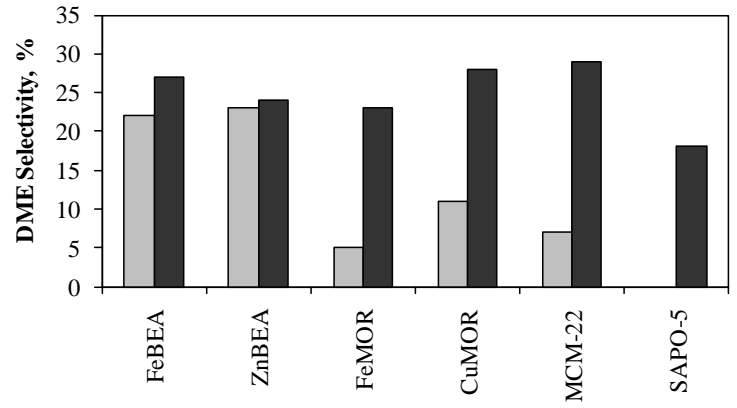

Figure 1. Selectivity to dimethyl ether using one ( $\square$ ) and two catalytic beds ( $\mathbf{a}$ )

The results with the two catalytic beds indicated that methanol dehydration to DME is favored over Brönsted acid sites present in the HZSM-5 zeolite. However, DME was also observed by the passage of the chloromethane flow over a single catalytic bed containing metal-exchanged zeolites ( 5 to $23 \%$ selectivity). It is known that on these catalysts, chloromethane is converted to an adsorbed methoxy species (scheme 2) (Fernandes et al., 2009; Murray et al., 1993; Wang and Hunger, 2008), which might be the key intermediate to methanol and dimethyl ether. Therefore, even over metal-exchanged zeolites the DME selectivity was increased by the inclusion of a second catalytic bed with HZSM-5 zeolite. Zeolites FeMOR and CUMOR presented DME selectivity higher than $20 \%$ with the use of a second catalytic bed, significantly higher than the results using only one bed (selectivity < $12 \%$ ). For FeBEA and ZnBEA zeolites, the use of a second catalytic bed did not significantly increase the DME selectivity. This finding can be explained by the $n$-butylamine thermodesorption results (Table 3 ). Both zeolites presented a higher distribution of strong acid sites, desorbing the base in the range between $623 \mathrm{~K}$ and $823 \mathrm{~K}$, indicating that these zeolites are strongly acidic and might possess Brönsted acid sites to dehydrate methanol to dimethyl ether. Therefore, the use of a second catalytic bed would not be so effective. For metal-exchanged Mordenites, the acidity results show a higher distribution of sites of moderate acid strength. Therefore, in this case, the presence of a second catalytic bed with HZSM-5 zeolite would increase the formation of DME. 
Table 3. Acid sites distribution measured by the thermodesorption of $n$-butylamine.

\begin{tabular}{|c|c|c|c|}
\hline Catalyst & $\begin{array}{c}\text { Weak acid sites } \\
\text { (mmol g } \text { of catalyst) }^{-1} \text { ) } 323 \text { to } 423 \mathrm{~K}\end{array}$ & $\begin{array}{c}\text { Moderate acid sites } \\
\text { (mmol } \mathrm{g}^{-1} \text { of catalyst) } \\
423 \text { to } 623 \mathrm{~K}\end{array}$ & $\begin{array}{c}\text { Strong acid sites } \\
\text { (mmol } \mathrm{g}^{-1} \text { of catalyst) } \\
623 \text { to } 823 \mathrm{~K}\end{array}$ \\
\hline CuMOR & 0.61 & 0.87 & 0.29 \\
\hline FeMOR & 0.44 & 0.45 & 0.55 \\
\hline ZnBEA & 0.60 & 0.67 & 0.93 \\
\hline FeBEA & 0.74 & 0.49 & 0.91 \\
\hline MCM-22 & 0.38 & 0.69 & 0,56 \\
\hline SAPO-5 & 1.17 & 0.38 & 0.32 \\
\hline HZSM-5 & $\mathrm{nd}^{\mathrm{a}}$ & 0.41 & 0.83 \\
\hline
\end{tabular}

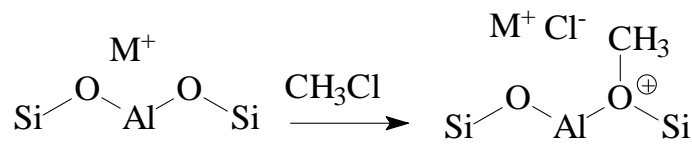

Scheme 2. Pictorial representation of chloromethane adsorption over metal-exchaged zeolites to afford a methoxy group.

The hydrolysis of chloromethane to methanol and DME can be accomplished in a single step, through the use of metal-exchanged zeolite catalysts, thus avoiding the high energy demand required for syngas generation. Although the conversions observed are still in the range of 5 to $10 \%$, they could be increased by varying the space velocity. Another approach would be the recycle of the non converted chloromethane, as usual in many types of industrial processes. One might argue that this route may have environmental drawbacks, associated with the release of chlorinated compounds to the atmosphere. Indeed, the $\mathrm{HCl}$ produced in the reaction could be used in the oxychlorination of natural gas to chloromethane (scheme 3). Thus, there would be no significant consumption or atmospheric release of chlorinated compounds, making the whole process attractive and environmentally clean. Since the oxychlorination is exothermic, the heat produced in the first step might be used in the catalytic hydrolysis, making the whole energy balance much more attractive than in the traditional natural gas reforming (syngas formation).

$$
\begin{aligned}
& 2 \mathrm{CH}_{4}+\mathrm{O}_{2}+2 \mathrm{HCl} \longrightarrow 2 \mathrm{CH}_{3} \mathrm{Cl}+2 \mathrm{H}_{2} \mathrm{O} \\
& 3 \mathrm{CH}_{3} \mathrm{Cl}+3 \mathrm{H}_{2} \mathrm{O} \stackrel{\text { Zeolite }}{\longrightarrow} \mathrm{CH}_{3} \mathrm{OH}+\mathrm{CH}_{3} \mathrm{OCH}_{3}+3 \mathrm{HCl}+\mathrm{H}_{2} \mathrm{O}
\end{aligned}
$$

Scheme 3. Schematic view of the chlorine-assisted conversion of methane to methanol/DME (oxychlorination and catalytic hydrolysis).

\section{CONCLUSIONS}

The hydrolysis of chloromethane to methanol and dimethyl ether can be carried out over metalexchanged zeolites at $543 \mathrm{~K}$. All catalysts tested showed better conversion than the blank reaction. Protonic zeolites, such as MCM-22 and SAPO-5, showed low selectivity to DME. Inclusion of a second catalytic bed with HZSM-5 zeolite increased the selectivity to DME. Acid strength measurements indicated that MCM-22 and SAPO-5 have weaker acid site distribution than HZSM-5, explaining the selectivity data for DME over these catalysts.

These results indicated that a technological route to methanol and DME from natural gas, avoiding syngas formation, is feasible with the use of chloromethane and metal-exchange zeolites as catalysts. This route might reduce the costs and energy consumption associated with syngas production. In addition, the $\mathrm{HCl}$ produced in the catalytic hydrolysis might be used for the oxychlorination of natural gas, thereby minimizing chlorine consumption and environmental contamination. 


\section{ACKNOWLEDGMENTS}

Authors thank FINEP/CTPETRO, Petrobras, CNPq, FAPERJ and PRH/ANP for financial support. We also thank Dr. Eledir Victor Sobrinho for synthesizing the SAPO-5 molecular sieve.

\section{REFERENCES}

Bidart, A. M. F.; Borges, A. P. F.; Nogueira, L.; Lachter, E. R.; Mota, C. J. A. Iron-exchanged zeolite as effective catalysts for Friedel-Crafts alkylation with alkyl halides. Cataylsis Letters, v. 75, p. 155157, 2001. doi:10.1023/A:1016748206714

Bucsi, I.; Olah, G. A. Selective monochlorination of methane over solid acid and zeolite catalysts. Catalysis Letters, v. 16, p. 27-38, 1992. doi:10.1007/BF00764351

Corma, A.; Corell, C.; Perez-Pariente, J. Synthesis and characterization of the MCM-22 zeolite. Zeolites, v. 15, p. 2-8, 1995. doi:10.1016/01442449(94)00013-I

Correa, R. J.; Mota, C. J. A. $\mathrm{S}_{\mathrm{N}} 2$, E2 reactions of butylchlorides on NaY zeolite: A potential method for studying the formation and reactivity of alkoxy species on the zeolites surface. Physical Chemistry Chemical Physics, v. 4, p. 4268- 4274, 2002.

Fernandes, D.R.; Rosenbach, N.; Mota, C.J.A. Chloromethane hydrolysis to methanol and dimethyl ether over metal-exchanged zeolite $Y$. Applied Catalysis A: General, v. 367, p. 108-112, 2009. doi:10.1016/j.apcata.2009.07.043

Franco, F.; Rosenbach, N.; Ferreira, G. B.; Guerra, A. C. O.; Kover, W. B.; Turci, C. C.; Mota, C. J. A. Rearrangement, nucleophilic substitution, and halogen switch reactions of alkyl halides over $\mathrm{NaY}$ zeolite: Formation of the bicyclobutonium cation inside the zeolite cavity. Journal of the American Chemical Society, v. 130, p. 1592-1600, 2008. doi:10.1021/ja0742939

Franco, M. J.; Mifsud, A.; Perez-Pariente, J. Study of SAPO-5 obtained from surfactantcontaining gels .1. Crystallization parameters and mechanism of Si substitution. Zeolites, v. 15, p. 117-123, 1995. doi:10.1016/0144-2449(94)00032-N

Gonçalves, V. L. C.; Pinto, B. P.; da Silva, J. C.; Mota, C. J. A. Acetylation of glycerol catalyzed by different solid acids. Catalysis Today, v. 133-135, p. 673-677, 2008. doi:10.1016/i.cattod.2007.12.037

Lersch, P.; Bandermann, F. Conversion of chloromethane over metal-exchanged ZSM-5 to higher Hydrocarbons. Applied Catalysis A: General, v. 75, p. 263-273, 1991.

Murray, D. K.; Chang, J. W.; Haw, J. F. Conversion of methyl halides to hydrocarbons on basic zeolites: A discovery by in situ NMR. Journal of the American Chemical Society, v. 115, p. 47324741, 1993. doi:10.1021/ia00064a037

Noronha, L. A.; Souza-Aguiar, E. F.; Mota, C. J. A. Conversion of chloromethane to light olefins catalyzed by ZSM-5 zeolites. Catalysis Today, v. 101, p. 9-13, 2005. doi:10.1016/j.cattod.2004.12.004

Olah, G. Q.; Gupta, B.; Farina, M.; Felberg, J. D.; Ip, W. M.; Husain, A.; Karpeles, R.; Lammertsma, K.; Melhotra, A. K.; Trived, N. J. Selective monohalogenation of methane over supported acid or platinum metal catalysts and hydrolysis of methyl halides over $\gamma$-alumina-supported metal oxide/hydroxide catalysts. A feasible path for the oxidaditve conversion of methane into methyl alcohol/dimethyl ether. Journal of the American Chemical Society, v. 107, p. 7097-7105, 1985. doi:10.1021/ja00310a057

Olah, G. A; Bukala, J. Antimony pentafluoride/graphite catalysed oxidative conversion of methyl halide with copper oxides (or cooper/oxygen) to dimethyl ether. Journal of Organic Chemistry, v. 55, p. 4289-4293, 1990. doi:10.1021/jo00301a016

Rosenbach, N.; Mota, C. J. A. Alkylation of Isobutane/2-Butene over Cation-Exchanged Zeolites. Journal of the Brazilian Chemical Society, v. 16, p. 691-694, 2005.

Ross, J. R. H. Natural Gas Reforming and $\mathrm{CO}_{2}$ Mitigation. Catalysis Today, v. 100, p. 151-158, 2005. doi:10.1016/i.cattod.2005.03.044

Sun, Y.; Campbell, S. M.; Lunsford, J. H.; Lewis, G. E.; Palke, D.; Tau, L. M. The catalytic conversion of methyl chloride to ethylene and propylene over phosphorus-modified Mg-ZSM-5 zeolites. Journal of Catalysis, v. 143, p. 32-44, 1993. doi:10.1006/jcat.1993.1251

Tijm, P. J. A.; Waller, F. J.; Brown, D. M. Methanol technology developments for the new millennium. Applied Catalysis A: General, v. 221, p. 275-282, 2001. doi:10.1016/S0926860X(01)00805-5

Wang, W; Hunger, M. Reactivity of alkoxy species on acidic zeolite catalyst. Accounts of Chemical Research, v. 41, p. 859-904, 2008. doi:10.1021/ar700210f

White, C. M.; Douglas, L. J.; Hackett, J. P.; Anderson, R. R. Characterization of synthetic gasoline from the chloromethane-zeolite reaction. 
Energy \& Fuels, v. 6, p. 76-82, 1992. doi:10.1021/ef00031a012

Xu, M.; Lunsford, J. H.; Goodman, D. W.; Bhattacharyya, A. Synthesis of dimethyl ether (DME) from methanol over solid-acid catalysts. Applied catalysis A: General, v. 149, p. 289- 301, 1997. doi:10.1016/S0926-860X(96)00275-X

Xu, H. F.; Wang, K. X.; Li, W. S.; Zhou, X. P. Dimethyl ether synthesis from methane by non syngas process. Catalysis Letters, v. 100, p. 53-57, 2005. doi:10.1007/s10562-004-3085-X

Zhou, X. P.; Yilma, A.; Yilmaz, G. A.; Lorkovic, I. M.; Laverman, L. E.; Wiss, M.; Sherman, J. H.; McFarland, E. W.; Stucky, G. D.; Ford, P. C. An integrated process for partial oxidation of alkanes. Chemical Communication, v. 18, p. 2294-2295, 2003. doi:10.1039/b307235e 